\title{
Assessment of left ventricular filling pressure using mean left atrial transit time from contrast enhanced dynamic MRI
}

\author{
JJ Cao ${ }^{*}$, Yi Wang, Jeannette McLaughlin, Elizabeth Haag, Michael Passick, Rena Toole, Joshua Y Cheng, \\ Justine Lachman, Nathaniel Reichek
}

From 2011 SCMR/Euro CMR Joint Scientific Sessions

Nice, France. 3-6 February 2011

\section{Introduction}

Left atrial (LA) size and function are often regarded as a reflection of left ventricular (LV) hemodynamics.

Purpose:In this study we investigated the hemodynamic correlates of contrast transit time within the left atrium (LA) in patients with LV systolic dysfunction by cardiac magnetic resonance imaging (CMR).

\section{Methods}

Ten subjects undergoing clinically indicated right and left heart catheterization and 48 subjects undergoing noninvasive evaluation were prospectively enrolled and brain natriuretic peptide (BNP) and N-terminal proBNP (NT proBNP) obtained prior to CMR examination. CMR was performed within 5 hrs of invasive hemodynamic assessment. Dynamic MR imaging was acquired in sagittal and coronal planes covering the LA using a saturation recovery SSFP sequence with bolus injection of $0.01 \mathrm{mmol} / \mathrm{kg}$ gadopentetate. Mean transit time was measured in the LA and normalized to heart rate. LV systolic dysfunction was defined as LV ejection fraction $(\mathrm{LVEF})<50 \%$. Noninvasive cohort also underwent echocardiography within 2 hours of CMR. Tissue Doppler was used to determine mitral E/e' ratio.

\section{Results}

Normalized mean LA transit time (nLATT) by CMR correlated strongly with LV early diastolic pressure $(\mathrm{r}=0.893, \mathrm{p}=0.001)$, end diastolic pressure (LVEDP) $(\mathrm{r}=0.909, \mathrm{p}<0.001)$ and mean diastolic pressure $(\mathrm{r}=0.936$, $\mathrm{p}<0.001)$ in the invasive cohort. In the noninvasive cohort nLATT was significantly prolonged in patients with LV systolic dysfunction $(\mathrm{N}=39) 10.1 \pm 3.0$ heart beats vs $6.6 \pm 0.7$ heart beats in normal controls $(\mathrm{N}=9)$ $(\mathrm{p}<0.001)$. In patients with LV systolic dysfunction average LVEF was $37 \pm 9 \%$ and the NYHA functional class 1.8 \pm 0.9 . Using a linear regression equation derived from the invasive cohort LVEDP was estimated in the noninvasive cohort which was divided into 3 subgroups: $\leq 10$ $\mathrm{mmHg}, 11-15 \mathrm{mmHg}$ and $\geq 16 \mathrm{mmHg}$. There were graded increases from low to high LVEDP subgroups in echocardiographic mitral medial E/e' ratio: $9 \pm 3,14 \pm 7$ and $18 \pm 13(\mathrm{p}=0.005)$; BNP: $53 \pm 41 \mathrm{pg} / \mathrm{ml}, 286 \pm 433 \mathrm{pg} / \mathrm{ml}$, $496 \pm 475 \mathrm{pg} / \mathrm{ml}(\mathrm{p}<0.001)$ and NT proBNP: $171 \pm 268$ $\mathrm{pg} / \mathrm{ml}, 712 \pm 948 \mathrm{pg} / \mathrm{ml}, 1249 \pm 1137 \mathrm{pg} / \mathrm{ml}(\mathrm{p}<0.001)$, demonstrating the concordance of nLATT with established noninvasive indices of hemodynamic status.

\section{Conclusions}

nLATT by dynamic MRI may be a valuable non-invasive marker of LV filling pressure in patients with LV systolic dysfunction.

Published: 2 February 2011

doi:10.1186/1532-429X-13-S1-P20

Cite this article as: Cao et al:: Assessment of left ventricular filling pressure using mean left atrial transit time from contrast enhanced dynamic MRI. Journal of Cardiovascular Magnetic Resonance 2011 13(Suppl 1):P20.

St Francis Hospital, Roslyn, NY, USA

(c) 2011 Cao et al; licensee BioMed Central Ltd. This is an open access article distributed under the terms of the Creative Commons 